\title{
Santo Domingo de Guzmán según Jerónimo Savonarola OP
}

\author{
The figure of Saint Dominic of Guzmán \\ according to Jerónimo Savonarola OP
}

Alfonso ESPONERA CERDÁN OP

Facultad de Teología San Vicente Ferrer

Valencia (España)

https://orcid.org/0000-0003-1370-7673

aespo.ar@dominicos.org

Abstract: The paper offers an approach to the figure of Saint Dominic of Guzman (+1221) by way of a little-known sermon by the famous Florentine Dominican Jerome Savonarola (1452-1498). This sermon helps us get to know not only the father founder of the Friars Preachers, but also the preoccupations of one of his most controversial sons, who later had an important influence in the Dominican Order.

Keywords: Saint Dominic of Guzman; Jerome Savonarola; Dominican Congregations for the Reform; Florence 15 th century.
Resumen: Se ofrece un acercamiento a la figura de Santo Domingo de Guzmán (+1221) según un muy poco conocido sermón del famoso florentino Jerónimo Savonarola, dominico (1452-1498). Ello va a posibilitar conocer no sólo al Padre Fundador de los Frailes Predicadores, sino también las inquietudes y preocupaciones de uno de sus controvertidos hijos, de importante influencia posterior en la Orden dominicana.

Palabras clave: Santo Domingo de Guzmán; Jerónimo Savonarola; Congregaciones dominicanas de observancia; Florencia siglo XV.

El dominico florentino Jerónimo Savonarola tiene un muy poco conocido sermón en el que brinda un acercamiento a la figura de Santo Domingo de Guzmán (h. 1174-1221) ${ }^{1}$ y por otra parte es expresión de las inquietudes y preocupaciones de este controvertido fraile que tuvo gran influencia en la Orden de Predicadores y en la Florencia, Italia y Europa del siglo XV y posteriores.

1 Un bastante completo repertorio bibliográfico de vidas en castellano publicadas a lo largo del siglo XX hasta 2003, en Humbert-Marie VICAIRE, Historia de Santo Domingo, Madrid, 2003, pp. 1314, n. 1; pero también, entre otros muchos: Michel RoQUEBERT, Santo Domingo. La leyenda negra, Salamanca, 2008, pp. 333-337; Vito-Tomás GómEZ García (ed)., Santo Domingo de Guzmán. Escritos de sus contemporáneos, Madrid, 2011, pp. 61-78. 


\section{SU AUTOR Y EL CONTEMPORÁNEO MOVIMIENTO DOMINICANO DE REFORMA}

Jerónimo Savonarola OP (1452-1498) en un principio no se dedicó a la predicación, sino a la enseñanza; y así empezó la explicación del libro del Apocalipsis, desarrollando el tema de la reforma de la Iglesia, iniciando un nuevo período de su vida y de la Historia de la ciudad de Florencia. Fue elegido Prior del Convento de San Marcos en julio de 1491, integrante de la Congregación de Lombardía, una de las Congregaciones dominicanas de observancia más florecientes.

Si bien la Reforma dominicana ya se puede datar con el Beato Raimundo de Capua hacia $1390^{3}$, según el cronista dominico Juan de la $\mathrm{Cruz}^{4}$ de la prédica y actividad de los dominicos Conrado de Prusia y Juan Dominici nació el fenómeno de las «Congregaciones de la Reforma»-específicamente la de Lombardía (1437) y la de Alemania (1465) - y también el binomio semántico observancia y conventualidad, de donde en los conventos que reformaron se comenzaron a llamar los frailes observantes y los otros quedaron con el nombre de claustrales o conventuales. Pero el Padre Mortier señaló que el término «conventualidad» no aparece en los cronistas dominicos del siglo XIV, pero sí en el siglo siguiente 5 .

El interesante tratado Pro Reformatione (1471) de Jean Uyt den Hove, primer Vicario General de la Congregación de Holanda, señala la siguiente diferencia entre observantes y no observantes:

Observantes dicuntur, que intendunt observancie predicte votorum e cerimoniarum, submittentes se penis taxatis pro transgressionibus, casu quo pro humana fragilitate defecerint. Non observantes autem dicuntur, illi qui passim et

2 La bibliografía sobre su vida y escritos es muy grande y se actualiza permanentemente, valga de ejemplo: Savonarola. Quaderni del quinto centenario (1498-1998). 3 vols., Bolonia, 1997. Entre otros muchos cfr. Armando VERDE y Donald WeInSTEIN, Savonarola. a vita, le opere, Vicenz, 1998; Roberto Ridolfi, Vita di Girolamo Savonarola, Firenze, 1981; además de las obras en sí, para bibliografía: Álvaro HUERGA, Savonarola. Reformador y profeta, Madrid, 1978, pp. XV-XXIII, Julia BENAVENT, Savonarola y España, Alzira, 2003, pp. 179-187.

3 Entre los múltiples trabajos sobre ella, cfr. Juan José GALlEgo SALVADORES, Aproximaciones a la Reforma dominicana de Raimundo de Capua y repercusiones en los dominicos de Portugal, en Arquivo Histórico Dominicano Português IV/2 (1989) pp. 219-249; Ramón HERNÁNDEZ MARTíN, La Reforma dominicana entre los Concilios de Constanza y Basilea, en Arquivo, pp. 151-179.

4 Citado por Guillermo NIEVA OCAMPO, Virtud christiana es grande, loar la memoria de los defuntos: historia de la Orden dominica y de su Reforma en la Crónica de fray fuan de la Cruz OP (1567), en Tiempos Modernos, 8 (2015) p. 363 n. 75.

5 Cfr. R.P. Mortier, Histoire des Maitres Généraux de l'Ordre des Frères Prêcheurs, t. III, Paris, 1907, p. 298; en las páginas siguientes traza una visión de los conventuales dominicos, partiendo de la Peste Negra (pp. 298-305). 
indifferenter transgrediuntur statuta et ceremonias, ut commedendo carnes, non tenendo silencium, non ieiunando, dormiendo super culcitras, utendo lineis ad carnem etc.; nullasque penas pro talibus defectibus portando, et quod peius est et penitus inexcusabile, habendo usum peculii indiferentem sive indeterminatum, ad nutum, in particulari, pro sua provisione personali ${ }^{6}$.

Quien además afirma que:

omnes Sancti canonizati de Ordine Fratrum Predicatorum, omnes Doctores qui solemniter scripserunt in Theologia, super Bibliam aut Sententias, in Iure Canonico, Logica, Physica, Grammatica, Historias, materias morales predicabiles, et generaliter omnes qui studio et exercitiis litterarum sunt famam celebrem assecuti, fuerunt vite regularis observantie amatores pariter et cultores. Recursus super hoc, ad legendas, registra et cronicas eiusdem Ordinis?.

Pero Savonarola quería más al respecto y por eso pensó formar una Congregación autónoma con algunos Conventos identificados con sus planteamientos. En 1492 consiguió el apoyo de las autoridades florentinas, incluso el de Pedro de Médicis, y el 22 de mayo de 1493 fue firmado por el Papa Alejandro VI el breve de separación.

Esta nueva «Congregación de San Marcos», celebró su primer Capítulo en 1494 y en él Savonarola fue elegido Vicario General, desarrollando sus ideas de reforma: pobreza absoluta, observancia estricta...; en pocas palabras, una vuelta a lo que consideraba el más genuino espíritu de Santo Domingo. Característica peculiar de estos Conventos fueron las prácticas piadosas de carácter eminentemente afectivo, que están expresadas iconográficamente por ejemplo en la deliciosa ronda de Santos y ángeles de uno de los Juicios del Beato Angélico -el pintor fr. Juan de Fiésole OP- en que aquellos se dirigen al Paraíso danzando y cogidos de la mano.

\section{CONSIDERACIONES PREVIAS SOBRE EL SERMÓN DE SAVONAROLA EN LA FIESTA DE SANTO DOMINGO}

El actual Propio de la Orden de Predicadores en su Liturgia de la Horas reformada conforme a los decretos del Concilio Vaticano II, en el Oficio de

6 R.M. MARTin (ed.), Tractatus Pro Reformatione. Lettre de fean Uyt den Hove OP, à Charles-leTéméraire touchant la réforme religieuse, en Analecta Sacri Ordinis Fratrum Praedicatorum, XXXI (1923) p. 301; Jean Uyt den Hove escribió esta carta a Carlos El Temerario, que más bien es un breve tratado escolástico, el 12 de octubre de 1471.

7 R.M. MARTin (ed.), Tractatus Pro Reformatione... [ver n. 6], p. 303. 
lecturas, para la segunda brinda cuatro, estando la última tomada de un «Sermón en la fiesta de Santo Domingo de fray Jerónimo Savonarola, presbítero» ${ }^{8}$, indicando que lo trae un artículo de Lodovico Ferretti OP publicado en $1910^{9}$, ofreciendo sólo seis párrafos del por lo menos para mí tan desconocido e interesante texto.

Intenté localizar el artículo en cuestión, lo cual fue bastante azaroso, pues la Edizione nazionale delle opere di Girolamo Savonarola (1965-1976, 20 vol.) no está a mi fácil alcance y ni la revista en las bibliotecas dominicanas. Finalmente Alejandro López Ribao OP y Dominik Jurczak OP, la localizaron en Roma en la antigua Biblioteca del convento de Santa Sabina y me la enviaron, por todo lo cual quiero manifestarles públicamente mi agradecimiento.

El citado trabajo de Ferretti tiene una breve introducción (pp. 381-383) y en páginas alternadas la versión latina original ( De Sancto Domenico»: pp. 384-400) y la traducción no muy textual en italiano actual ( $\ll$ Su San Domenico»: pp. 385-401) ${ }^{10}$. En el florentino Convento de San Marcos en aquel 1910 se conservaba entre otros recuerdos de Savonarola un códice, que perteneció un tiempo a su amigo Girolamo Benivieni y después a Girolamo Gondi, que contenía muchos esquemas y escritos muy valiosos, todos de su mano, entre los que se encontraba este sermón en latín. Para Ferretti, era inédito y muy poco conocido ${ }^{11}$.

Poco más puede saberse de sus circunstancias históricas a no ser que lo pronunció ante frailes dominicos del observante Convento de San Marcos, de Florencia, como Prior que era, y en la fiesta de Santo Domingo de Guzmán; si fue en 1492 u otro año, se desconoce.

Por otra parte, está en latín culto y destinado a gente formada en Teología pues por ejemplo aduce afirmaciones de Tomás de Aquino en su Suma Teológica. En varios momentos pone la expresión «etc.», lo que indica que tanto

8 Cfr. Propio de la Orden de Predicadores, Liturgia de las Horas, edición típica en lengua española, Roma, 1988, pp. 881-883.

9 Lodovico Ferretti (ed.), Nella Festa di San Domenico. Sermone ineditto di Fra Guirolamo Savonarola tratto dall'autografo, en Il Rosario-Memorie Domenicane, 27 (1910), pp. 381-401.

10 «Che fedelmente trascritto pubblichiamo nel testo originale con traduzione volgare a fronte» (Lodovico FerretTi (ed.), Nella Festa... [ver n. 9], p. 381). Puede llamar la atención la indicación sobre la traducción, pero no debe olvidarse que no es el italiano que hablaba Savonarola, cfr. Vittorio COLETTI, L'Italiano e il modello omiletico di due predicatori a confronto: San Bernardino $e$ Girolamo Savonarola, en The Church and the languages of Italy before the Council of Trent, Toronto, 2015, pp. 26-44.

11 Cfr. Lodovico Ferretti (ed.), Nella Festa... [ver n. 9], p. 381. 
él como otros posibles usuarios podían ampliar ese punto, así como señala -como otros predicadores escolásticos bajomedievales- «notad su sentido misterioso», en el sentido de «lo más profundo», y tiene un abundante uso de la Sagrada Escritura.

Es una auténtica clase de Teología según la doctrina de Tomás de Aquino y otros teólogos, pues no hay que olvidar que él fue profesor. Así por ejemplo, se verá que utiliza los diversos sentidos de las Escrituras (histórico o literal, alegórico, moral y escatológico), brinda la tradicional teología de los Estados de Perfección, menciona el tema del inminente fin del mundo -tema tan querido por los primeros dominicos y franciscanos- pero no lo desarrolla, aunque entiende que se está viviendo la última etapa de la Historia. Por otra parte, denuncia a los malos Obispos y clérigos, y más ligeramente a los malos religiosos y a ciertas costumbres de aquella sociedad.

Como se observará, parte del texto del libro del Eclesiástico (o Sirácida) en la versión de la Vulgata 50,1-10, que aparece en los capitula del Oficio Litúrgico dominicano de su Fiesta antes de la reforma litúrgica del Concilio Vaticano II. Irá versículo por versículo aplicándolo a Domingo de Guzmán, señalando pasajes de su «hystorica dicta» así como otros textos, que no trascribe el sermón.

A continuación para facilitar la comprensión, se trascribe el señalado texto bíblico según la Vulgata ${ }^{12}$, pues es el que va seguir versículo a versículo el florentino, si bien en este trabajo aparecerá en castellano:

1. Sacerdos magnus, qui in vita sua suffulsit domum, et in diebus suis corroboravit templum. 2. Templi etiam altitudo ab ipso fundata est, duplex ædificatio, et excelsi parietes templi. 3. In diebus ipsius emanaverunt putei aquarum, et quasi mare adimpleti sunt supra modum. 4. Qui curavit gentem suam, et liberavit eam a perditione; 5. qui prævaluit amplificare civitatem, qui adeptus est gloriam in conversatione gentis, et ingressum domus et atrii amplificavit. 6. Quasi stella matutina in medio nebulæ, et quasi luna plena, in diebus suis lucet: 7. et quasi sol refulgens, sic ille effulsit in templo Dei. 8. Quasi arcus refulgens inter nebulas gloriæ, et quasi flos rosarum in diebus vernis, et quasi lilia quæ sunt in transitu aquæ, et quasi thus redolens in diebus æstatis: 9. quasi ignis effulgens, et thus ardens in igne; 10 . quasi vas auri solidum, ornatum omni lapide pretioso.

Por otra parte, si bien el sermón se va a seguir en versión castellana que he realizado ex profeso, para no multiplicar las notas al pie, las referencias de las páginas del texto original latino utilizado se indicarán en el cuerpo. 


\section{CONTENIDOS FUNDAMENTALES DEL SERMÓN}

Este es el gran sacerdote que durante su vida reparó la casa y en sus días fortificó el Templo (Si 50,1). Este es, hermanos, el bienaventurado Domingo, cuya fiesta hoy celebramos y que nació en una región del Occidente cuando se acercaba el fin del mundo y que, junto con el Bienaventurado Francisco, renovó la Iglesia que se estaba derrumbando ${ }^{13}$, pues nació en tal tiempo. Ved lo que dicen el Breviario al respecto ${ }^{14}$ y la Historia: «Envió, dice, a su siervo a la hora de la cena» (Lc 14,17). La hora de la cena es el fin del mundo. Nosotros, pues, nos hallamos en la etapa final de los siglos. Y por tanto, fue enviada la nueva Orden a la hora de la cena, es decir en los tiempos finales ${ }^{15}$ (cfr. 384).

A continuación señala que sus oyentes al ver a la Iglesia derrumbarse desearon que viniesen predicadores de ese tipo. E inicia un diálogo retórico interpelándoles: ¿es que hoy no hay ilustres predicadores, doctos, elocuentes, perito en las diversas Artes, sutiles, hombres buenos? ¿Por qué pues no se convierten los hombres? Respondiendo que si hicieran milagros como los Padres antiguos, se convertirían. Y es que los Apóstoles y los otros Santos renovaron el mundo, ¿cuál fue la causa principal de tal hecho: los milagros o la vida? (cfr. 384).

Seguidamente hace una amplio excursus sobre el sentido de los milagros, sobre todo si no van acompañados por la vida, aduciendo en un momento una afirmación de Tomás de Aquino en su Suma Teológica (I-II, q. 113 a. 10). Concluyendo: No digas, hermano, que si los predicadores hicieran milagros el pueblo se convertirá. Di más bien, que si los predicadores y Prelados de la Iglesia vivieran bien, todas las cosas serán restauradas. Observa pues que el pueblo quiere conocer la vida de los sacerdotes. Del Bienaventurado Domingo se lee que sustentaba la iglesia de San Juan de Letrán que amenazaba ruina. Y remite a la Hystoriam del sueño de Inocencio III al respecto a fines de $1215^{16}$ (cfr. 386).

13 Esta imagen de la Iglesia derrumbándose y que Domingo apoya con sus hombros, o sea con su vida y palabra, volverá más adelante.

14 «Praeco novus et caelicus missus in fine saeculi, pauper fulsit Dominicus...» (Antífona del I Nocturno del Oficio Litúrgico dominicano de su Fiesta, antes de la reforma del Concilio Vaticano II); «Vergente mundi vespere, novum sidu exoritur...» (Himno de Laudes del mismo Oficio Litúrgico).

15 Cfr. Humberto de Romans, Narración sobre Santo Domingo, Prólogo, en Vito-Tomás GómeZ García (ed.), Santo Domingo de Guzmán: Escritos de sus contemporáneos, Madrid, 2012, p. 503 (la citaré por esta edición indicando el número del párrafo y la página).

16 Cfr. HumberTo De Romans, Narración... [ver n. 15], nº 30, p. 524. 
Posteriormente cita el texto bíblico tomado del libro del Eclesiástico: Este es el gran sacerdote (Si 50,1a). Considerad, hermanos, estas palabras y notad su sentido misterioso ${ }^{17}$. Los sacerdotes son muchos pero pocos, porque muchos son en número pero pocos en obras (cfr. J. Crisóstomo, Super Mattheum, homilía XXV). Y, por otra parte, no todos los sacerdotes buenos, son notables (magna). Sn embargo el sacerdote debe iluminar al pueblo, pues a él le corresponde verdaderamente predicar. ¿Y cómo puede darse un sacerdote que no sepa iluminar? Más aún, ¿cómo puede darse un sacerdote que ni siquiera esté él mismo iluminado, aunque sea un mal sacerdote? El Bienaventurado Domingo era Santo y era iluminado por la doctrina (cfr. 386).

Pero alguien podrá decir: Yo me preparo para predicar Santamente. Hoy día nuestros sacerdotes quieren todos el oficio de predicar, porque tal oficio se tiene en gran honor, y dicen que para ello estudian sermonarios y otros libros para con ello edificar al pueblo. Alguno quizá diga que al menos haré algún bien a la Iglesia.

Además, ¿qué dice a continuación el texto de la Escritura?: Durante su vida reparó la casa (Si 50,1b), esto es en el tiempo de su vida. Pero la vida pecadora no es vida, sino muerte. Quiere decir en su vida Santa, o sea por su vida y buen ejemplo. Rogad, rogad, pues, al Señor que envíe buenos y Santos sacerdotes que sostengan la casa, es decir la Iglesia entera, amenazada de gran ruina (cfr. 386 y 388).

En sus días consolidó el Templo (Si 50,1c). Se pregunta qué quiere decir este versículo, respondiendo que primeramente la vida sustenta a la Iglesia y después la doctrina. Y por templo se entiende todo el clero porque está en el templo Santo en cuanto casa y el clero debe ser más Santo que el pueblo y más iluminado por la doctrina.

Después pasa al versículo: Él echó los cimientos de la doble altura [o torres de refuerzo] (Si 50,2a). La altura de este templo hace referencia al estado de perfección de algunos que forman parte del clero, es decir de los religiosos. Es cierto que el obispo debe ser perfecto porque está en estado de perfección. Pero también los religiosos están en estado de perfección porque han profesado los votos y se han obligado a hacer lo que conduce a la vida perfecta. Pero no digo que clérigos y seglares no puedan ser perfectos en vida como los religiosos, sino que no están en un estado de perfección ni son perfectos. El Bienaventurado Do-

$17 \ll$ Misterioso» en el sentido de profundo, a desentrañar, que por ejemplo San Vicente Ferrer también utiliza muy frecuentemente en sus sermones. 
mingo fundó en la doble altura del templo la Orden de Predicadores. Añadiendo: aquí puede hablarse de cómo instituyó la Orden y cómo la Santísima Virgen dio su hábito ${ }^{18}$ (cfr. 388).

Echó los cimientos de la doble altura -porque instituyó dicha Orden tanto de varones y como de mujeres- del alto contrafuerte del Templo (Si 50, 2b). Los cimientos son los doctores y predicadores que custodian y están en el templo, esto es en la Iglesia y en la Religión de los Predicadores, y que son excelsos por la contemplación y la Santidad de vida. Consideremos pues, hermanos, en qué estado estamos. En efecto, no nos contamos entre el pueblo, pues debemos tener más Santidad de vida que el pueblo. Por tanto avergoncémonos si tenemos más avaricia que el pueblo, más vanidad, sensualidad, ambición y otros pecados, etc. También como pertenecemos al clero, debemos ser más perfectos que los clérigos. ¡Qué vergonzoso es que los clérigos seculares sean más devotos, más solitarios y más dados a la oración y ayunos, etc.! Pero incluso entre los religiosos, pues somos la Orden de Predicadores (cfr. 388).

Cuán perfectos deban ser esos Predicadores se deduce de lo que dice más adelante: el alto contrafuerte del Templo. ¿No es por ventura, hermanos, causa de vergüenza si alguien, considerando el prestigio del Arte que ejerce no es consecuente con él, como cuando un soldado tiene miedo o huye? ${ }^{19}$ Considerad, pues, también vosotros vuestro nombre, pues como os dije el año pasado vuestra Regla consiste en tres palabras ${ }^{20}$ (cfr. 388.390).

Después pasa a glosar el versículo siguiente: En sus días fue excavado el pozo de las aguas, un estanque amplio como el mar (Si 50,3). Sobre pozos leemos muchas cosas en las Escrituras, entre ellos los que excavó Isaac según Génesis 26 (15,25). ¿Qué significa pozo según las Escrituras? Pueden llamarse pozo y pozos, porque la Escritura se refiere a la causa eficiente, material, final y formal; esto es, a solo Dios y a uno tiende y uno es el modo de decir y de tratar que salva en todas partes. Pero además, las Escrituras tienen dos partes principales y cada una de ellas muchas otras, esto es el Nuevo y Antiguo Testamento y los Profetas y Evangelis-

18 Cfr. Humberto de Romans, Narración... [ver n. 15], no 30, pp. 524-525. Fue una tradición muy antigua que la Virgen María dio el nuevo hábito -más exactamente, sería el escapulario- al Beato Reginaldo de Orleáns, según lo recogía Jordán de Sajonia en sus Orígenes de la Orden de Predicadores n 57 (en Vito-Tomás Gómez GARCía (ed.), Santo Domingo... [ver n. 15], p. 235), si bien desde los principios de la Orden fue el hábito blanco y negro que llevaban los Canónigos Regulares así como los cistercienses y que Santo Domingo nunca lo cambió.

19 Añadiendo que se puede hablar de la práctica, ejercicio, de cualquier Arte.

20 Alude a un sermón que tuvo el año anterior en las mismas circunstancias (lugar, día y oyentes), pero que Ferretti no encontró (cfr. Nella Festa... [ver n. 9], p. 390 n. 1). 
tas, este es un pozo y los muchos pozos. De lo que se sigue que muerto Abrahán, esto es Cristo y sus Apóstoles que fueron padres de muchas gentes, surgieron los palestinos, esto es herejes y profetas que cavaban pozos en la tierra, o sea, los sentidos terrenales y carnales, y alteraban con falsas escrituras (cfr. 390).

Pero por Abrahán surgió Isaac, como se dice: «a tus padres sucederán tus hijos» (Sal 44,17), esto es, otros doctores como Agustín, Jerónimo, etc. Y cavaron pozos como lo había hecho Abrahán, o sea descubrieron sentidos de la Escritura como habían enseñado los antiguos Padres. Pero los herejes no los aceptaban, aunque muchos Doctores de la Iglesia los cavaban. En el tiempo del Bienaventurado Domingo la Iglesia estaba llena de herejes. Entonces él como Isaac, surgió y vendió sus libros y fue hecho Canónigo Regular. Indicando que se puede hablar del episodio en Palencia hacia 1196 de la venta de los manuscritos utilizados para estudiar por el joven Domingo, para de lo obtenido darlo a los pobres así como su posterior ingreso como Canónigo Regular en la catedral de Osma ${ }^{21}$.

Vino después de él, el Bienaventurado Pedro Mártir (o Pedro de Verona), mientras los herejes seguían cavando pozos, etc. Sin embargo, los inquisidores detuvieron la guerra y el Bienaventurado Tomás de Aquino ${ }^{22}$ fue quien silenció a todos, expandiéndose sus enseñanzas. Por eso bien puede decirse: «Excavaron otro pozo por el cual no lucharon; entonces llamó a aquel lugar diciendo: Ahora nos lo ha dado Dios y nos hará crecer sobre la tierra» (Gn 26,22). Por tanto bien dice nuestro texto: En sus días fue excavado el pozo de las aguas ( $\mathrm{Si}$ 50,3a), porque todas las ciencias se difundieron por toda la Iglesia y están los varones doctísimos en todas las Facultades, como las aguas del mar, esto es las doctrinas (cfr. 390.392).

Y porque excluidos los errores, permanece la Sana doctrina por la que el pueblo se cura de la enfermedad de los pecados, es acertado lo que sigue: Preocupado por su gente, la liberó de la perdición (Sir 50,4). Pero si dices: Yo ya estaba muerto y por tanto no estaba en sus días, ¿cómo puede venirme tal cosa? Puede decirse que el Bienaventurado Domingo fue como Adán en el que estaba toda la Humanidad, así en él estaba toda la Orden como su principio. Así como el pecado estaba en todo el cuerpo por uno, la justicia original por lo mismo está en nosotros si no pecamos. Por los méritos y gracia del Bienaventurado Domingo principalmente vinieron a la Orden todos los bienes así como por Abrahán, que fue principio del pueblo hebreo, fueron hechos también en dicho pueblo. Por lo que el Señor frecuentemente dice: «Por Abrahán, mi siervo...» (Gn 26,24). Igual-

21 Cfr. Humberto de Romans, Narración... [ver n. 15], nº 7.8, pp. 508.509.

22 Sobre su reflexión sobre la identidad dominicana, cfr. Antonio SANCHIS QUEVEDO, Estudios espirituales de Santo Tomás, en Teología Espiritual, 6 (1962), pp. 277-315. 
mente a los reyes de Jerusalén frecuentemente dice el Señor que no quiere hacer mucho mal sino que quiere hacer mucho bien «por David», que fue la cabeza de ellos. Y si dices que solo Cristo es quien ha merecido para otros, respondo que es exacto por verdadero y propio mérito (ex condigno), porque verdaderamente es la cabeza de todos y mediador entre Dios y los hombres, que padeció por nuestra salvación. Pero otras cabezas merecen para otros por conveniencia (ex congruo), porque es conveniente que haga una lo que otros hacen para la perfección de vida que se encuentra en ella (cfr. 392)

Tanta fue la Santidad y los méritos del Bienaventurado Domingo que no hay palabras para predicarlos. Dice el proverbio: L'opera loda il maestro (el trabajo alaba al maestro). ¡Ved la Orden que instituyó, cómo se expandió en número y mérito, lo que es suficiente para alabarla y exaltarla! Suficiente para que todos lo vean, sin ser necesario mostrar alguna cosa más para que alguien claramente la vea. De donde se sigue: Que sobresalió agrandando la ciudad (Sir 50,5a), esto es la Iglesia con los Predicaciones al convertir a muchos a la fe y también dilatando mucho la Orden por el universo (cfr. 392.394).

¿Qué glorioso era rodeado de su pueblo! (Si 50,5b). Se dice del Bienaventurado Domingo $^{23}$ que su trato siempre resultaba alegre y abierto, por lo que era amado por todos con afecto profundo. Quiso, efectivamente, que sus conventos fueran edificados en las ciudades para tratar con todos los hombres y ser útil a todos. Por eso gastaba el día con los prójimos y la noche con Dios (cfr. 394)

$Y$ amplió el ingreso de la casa y del atrio (Si 50,5c). Donde debe indicarse que por atrio deben entenderse los bienes temporales que hacen una vida más larga; mientras la casa son los que se conservan estrictos, como los religiosos. El ingreso a ambas vidas es el Evangelio, que el mismo Domingo difundió con su vida y doctrina porque predicaba la caridad que dilata el corazón y lo hace todo fácil. «Tu mandato, Señor, se dilata sin término», dice el salmo (Sal 118, 96); y también: «Correré por el camino de tus mandatos cuando me ensanches el corazón» (Sal 118, 32); por eso cuando alguien le preguntó dónde encontraba explicaciones tan justas, él respondió: «En el libro de la caridad» ${ }^{24}$.

23 Todo lo que indica a continuación se basa en múltiples pasajes de la citada obra de Humberto de Romans.

24 Gerardo de Frachet cuenta que «un estudiante le preguntó en qué libros estudiaba, pues lo veía predicar óptimamente y disertar a su gusto acerca de la Sagrada Escritura. El varón Santo le respondió: «Hijo, he estudiado en el libro de la caridad más que en ningún otro, pues este enseña de todo» (Vidas de los hermano, nº 42, en Vito-Tomás GómEZ García (ed.), Santo Domingo... [ver n. 15], p. 698). 
Sin embargo decís: « Qué angosto es el camino que lleva a la vida!» (Mt 7,14). Verdad es si solo miráis lo exterior; pero si miráis la caridad: «mi yugo -dice- es suave y mi carga leve» (Mt 11,29). Amando nada es difícil. ¡Venid, hijos, e ingresar en la casa o en el atrio, porque el ingreso ha sido ampliado! Teniendo caridad nada es difícil, porque «la caridad es paciente, es benigna» (1Cor 13,4). Pero vosotros, hermanos, que queréis estudiar la Escritura, que queréis predicar, no estéis todo el día alrededor de los estudios y comentarios. Tened caridad y ella os instruirá. ¿Qué quiere decir? Que la caridad os hará entender la caridad; la caridad conoce la caridad y está presente con la caridad y habla con ella. La Escritura no es sino caridad. Teniendo caridad, entiendes a la caridad. Cuándo alguien habla ¿se entiende a sí mismo? El que hable una lengua extranjera ¿lo entenderá? Por tanto es imposible que el que tiene caridad no entienda la Escritura en cuanto necesaria para la salvación y es imposible que no tenga caridad para entenderla. «El fin del Evangelio es la caridad de un corazón puro» (1Tm 1,5) (cfr. 394.396)

Después pasa a Como la estrella de la mañana en medio de nubes (Si 50,6a). Señala que: a) algunos en la Iglesia no tienen ni vida ni doctrina; b) otros tienen vida y doctrina; c) otros poseen vida, pero no doctrina; y d) otros doctrina, pero no vida.

Los primeros son semejantes a los animales que viven de imaginaciones y memorias, como el Filósofo Aristóteles dice también del arte y de la razón del hombre. En efecto, si se sigue solo el sentido y la sensibilidad, ¿por qué otra cosa se es diferente de los brutos? Pues no se ama sino lo que se puede ver, u oír, o imaginar. Sin embargo los Santos aman «lo que el ojo no vio, ni el oído oyó» (1Cor 2,9).

Los segundos son semejantes a los ángeles y a Cristo, En primer lugar por la perfección de la bienaventuranza porque ya están casi tocando la última perfección de la bienaventuranza, según aquello de: «Bienaventurado el que alcanza la sabiduría» (Prov 3,13). También por sublimidad, porque ya participan de la amistad de Dios y de los Santos y por la semejanza que es causa del amor, donde están sublimes los cuasi amigos del rey eterno. «Inagotable tesoro es para los hombres y los que de él se aprovechan son partícipes de la amistad de Dios» (Sab 7,14). Finalmente, por placidez, alegría. «No es amarga su conversación, ni dolorosa su convivencia, sino alegría y gozo» (Sab 8,16).

Los terceros -los que tienen vida, pero no doctrina- son semejantes a navecillas existentes en medio del mar que no tienen gobernador y a no ser que se acerquen a un navío grande y les lleve, están en gran peligro. Por eso está escrito: «Estaban arando los bueyes y pacían cerca de ellos las asnas» (Job 1,14). Esto es, vosotros, los simples, no deseéis ser maestros y cuidaos de los que no tienen doctrina con experiencia y Santidad. 
Los cuartos son semejantes al diablo y por eso gravemente serán flagelados como él, porque «el siervo que conociendo la voluntad de su amo, no se preparó ni se hizo conforme a ella, recibió muchos azotes» (Lc 12,47) (cfr. 396)

Por tanto, grandes son en la Iglesia los que tienen doctrina y vida. Pero puedes decir: Alguno tiene doctrina y vida, pero no enseña. Difícil que encuentres alguno, porque «nadie enciende la lámpara y la pone en un rincón, ni bajo el celemín, sino sobre un candelero, para que los que entren tengan luz» (Lc 11,33).

En el Evangelio de hoy (cfr. Mt 5, 13-20), que es la fiesta de nuestro Padre, se canta: $1^{\circ}$ indicando que la vida del predicador es lo primero que se requiere, dice: «Vosotros sois la sal de la tierra», pues efectivamente es un condimento para los hombres; $2^{\circ}$ indicando la doctrina, dice: «Vosotros sois la luz del mundo»; $3^{\circ}$ queriendo mostrar que Dios estos dos no los ha creado para esconderlos, sigue inmediatamente: «No puede esconderse una ciudad», etc. De donde también si un varón Santo y docto huye a las selvas, será encontrado como Jerónimo y muchos otros que huyeron pero no pudieron permanecer escondidos. Y si dices: Hoy hay muchos escondidos. Te digo que no deben ser fervientes, porque Cristo no puede mentir. Pues por parte de Cristo no da la gracia gratis data con la Santidad si no es para utilidad de la Iglesia. Por otra parte, si los Santos contra el precepto de Cristo no enseñaran, pecarían porque está escrito: «Al que acapara el trigo, le maldice el pueblo» (Prov. 11,26). Pero muchos son los que ni doctrina ni Santidad tienen y quieren manifestarse ellos mismos en lo que no tienen ${ }^{25}$. Porque los que son Santos y doctos, maestros y otros iluminadores, son dignos de excelsa gloria aquí y en el futuro, según muestra el Señor cuando dice: «Pero el que practicare y enseñare, éste será grande en el Reino de los Cielos» (Mt 5,19) (cfr. 396 y 398).

Tal fue el Bienaventurado Domingo del que bien se dice: Como la estrella de la mañana en medio de nubes (Si 50,6a). En efecto, en medio de los herejes lucía como estrella de la mañana. Háblese de la estrella que se pintó en su frente ${ }^{26} \mathrm{y}$ cómo combatió contra los herejes. Porque es difícil estar entre pecadores y no mancharse, y por eso dice a continuación: Como Luna llena luce en sus días ( $\mathrm{Si}$

25 Añade: «Practica contra istos, etc.», o sea, poner ejemplos concretos.

26 Cfr. Humberto de Romans, Narración... [ver n. 15], nº 4, 506. Además de esta estrella (atributo luminoso), los otros atributos iconográficos tradicionales de Santo Domingo de Guzmán son el hábito (atributo de religioso), el libro (atributo intelectual), el perro con la antorcha encendida (atributo de predicador) y el Rosario (atributo mariano), y a veces el bastón y el cuchillo (cfr. Domingo ITURGÁIZ, Iconografía de San Domingo de Guzmán. La fuerza de la imagen, Archivo Dominicano, 12 [1991], pp. 5-125). 
50,6b), como decir: en nada era deficiente como Luna llena. Porque uno no falla en sí mismo, pero falla en el vigor de la iluminación de los otros porque está entre los enemigos, al querer mostrar cuán eficaces son sus palabras. Por eso dice: Asi como el Sol refulge, porque su virtud resplandece en las nubes, asi él refulge en el templo de Dios (Si 50,7) (cfr. 308.400).

Y porque el Bienaventurado Domingo entre los gloriosos predicadores fue gloriosísimo y sus palabras eran agudísimas, le conviene bien lo que sigue: Como Arco [Iris] brilla entre las nubes de la gloria (Si 50,8a). En efecto, las nubes de la gloria son los predicadores auténticos y gloriosos a los cuales compete la aureola de la gloria, esto es que predicaron por el honor de Dios y la salvación de las almas. Entre los que el Bienaventurado Domingo refulge como Arco Iris entre las nubes porque roja es la caridad, verde la contemplación y blanca es la pureza que como agudas saetas emite al mundo. Y porque no temía a los adversarios de Cristo, sino que con confianza anunciaba la verdad y anhelaba el martirio ${ }^{27}$, por ello bien sigue: Como rosa en los días de primavera ( $\mathrm{Si} 50,8 \mathrm{~b}$ ). Efectivamente, la rosa entre espinas no se mancha, sino que rutila. Y porque entre los varones y mujeres conservó el lirio de la virginidad, sigue: Como lirio junto a un manantial (Si 50,8c). Y porque continuamente estaba en oración y dijo que cualquier cosa que pedía a Dios lo obtenía, se sigue: Como brote de planta de incienso en los días de verano ( $\mathrm{Si} 50,8 \mathrm{~d}$ ), porque la oración manda olor en el tiempo de la caridad que la inflama. Y porque su predicación era tan ardiente y luciente, se dice: Ardía como fuego (Si 50,9a); por lo que se canta de él: Arde como una antorcha, por el celo por los que perecen ${ }^{28}$. Porque todo él estaba totalmente dado al amor del prójimo para traerlo al buen camino mediante la predicación y el ejemplo de su vida, por ello mismo pudo ofrecerse a Dios como sacrificio de suave olor (cfr. Ef 5, 2), y por eso continúa: E incienso en el incensario (Si 50, 9b); es decir: en el fuego del Espíritu Santo y en el del amor al prójimo y en el de las tribulaciones, pues todo ello subía a la presencia de Dios como un olor suavísimo. Concluyendo, se hizo todo caridad, sabiduría y estuvo adornado de todas las virtudes, y por eso sigue: Como vaso de oro macizo, adornado con toda clase de piedras preciosas (Si 50,10).

Así pues, consumado y perfecto con toda virtud, fue recibido con triunfo en el Cielo. Y señala Savonarola, ahora se habla de su muerte ${ }^{29}$.

27 Cfr. Humberto de Romans, Narración... [ver n. 15], nº 24, pp. 518-519.

28 Del Himno de las Primeras Vísperas del Oficio Litúrgico dominicano de su Fiesta, antes de la reforma del Concilio Vaticano II.

29 Cfr. HumberTo de Romans, Narración... [ver n. 15], nº 67-70, pp. 554-556. 


\section{CONCLUSIONES}

El «espíritu» savonaroliano puede caracterizarse entre otros, por estos rasgos: la meditación de la Pasión de Cristo; la austeridad de vida; la urgencia de una inminente reforma de la Iglesia; la restauración del rigor primitivo de la Orden con la observancia estricta de las Constituciones, viviendo en absoluta pobreza y en la oración asidua, sin abandonar por eso ninguno de los ministerios propios de la profesión dominicana, especialmente la predicación. Todos ellos son el substrato directa o indirectamente en este sermón y en otras obras suyas y sermones ${ }^{30}$.

En cuanto a la figura de Santo Domingo de Guzmán, ha podido observarse que no sigue un orden cronológico en la presentación de los pasajes de su vida, sino de acuerdo a las necesidades temáticas que va exponiendo.

Por otra parte, remite a pasajes de su vida, posiblemente a Humberto de Romans y su Legenda maior Sancti Dominici (1256), porque -como sus contemporáneas de Pedro Ferrando y Constantino de Orvieto, de quienes H.de Romans depende casi literalmente- tenía una finalidad litúrgica, que le hacía ser muy conocida por los frailes, pues la utilizaban para las lecciones de Maitines y para las lecturas que se hacían en el Capítulo conventual y refectorio.

Pero no utiliza la Legenda Aurea (hacia 12292), del también dominico Jacobo de la Vorágine, muy empleada por los predicadores hagiográficos desde su aparición. Y es que la producción historiográfica había registrado en el XIII decisivas novedades culturales. Pasiones y vidas de Santos, antiguos y nuevos, fueron objeto de reescritura y escritura destinada ya no al uso litúrgico y a la lectura monástica comunitaria, sino a la predicación de las nuevas Órdenes o a la lectura privada de los laicos, reunidas en las llamadas legendae novae o legendarios abreviados, siendo el más famoso entre todos ellos, por su difusión y por su traducción en lengua vulgar ${ }^{31}$. Eran recursos nuevos como instrumentos y nuevos por su puesta al día hagiográfica.

30 Según Álvaro Huerga (cfr. Aproximación a la espiritualidad de Savonarola, en Angelicum 60 [1983], pp. 80-96) su espiritualidad le lleva a ser: maestro de la vida cristiana; sus fuentes son la Biblia y Santo Tomás de Aquino; dialéctico excelente, de rigurosa estructura lógica doctrinal; con abundantes consejos prácticos.

31 Cfr. la traducción castellana de José Manuel MACías, La leyenda dorada, 2 vols., Madrid, 1990; fue una de las obras de autor, dirigidas a la construcción de específicos panteones institucionales de cada una de las Órdenes y también territoriales, con el objetivo de sacralizar la ciudad, las regiones, las naciones. Véanse, entre otros: Alain BOUREAU, La légende dorée. Le système narratif de Facques de Vorágine, París, 1984, y el trabajo póstumo de Jacques LE GOFF, A la recherche du temps sacré. Facques de Vorágine et la Légende dorée, París, 2011, ensayo en el que propone una nueva 
Ha podido observarse que los rasgos de Santo Domingo que destaca Savonarola $\operatorname{son}^{32}$ : vir evangelicus: Santo e iluminado por el Evangelio; gastaba el día con los prójimos y la noche con Dios; estudió en el «libro de la caridad»; unió vida y doctrina; in medio Ecclesiae: predicador y fundador; al servicio de la Iglesia; su Orden era de religiosos basados en la contemplación, el estudio y la predicación, vinculados con la Virgen María; combatió a los herejes; anunció la verdad y anheló el martirio. Concluyendo, que se hizo todo caridad, sabiduría y estuvo adornado de todas las virtudes, consumado y perfecto con toda virtud, fue recibido con triunfo en el Cielo. Señala además, que tanto él como su Orden fueron enviados en los tiempos finales.

En síntesis: para el florentino, Santo Domingo iluminaba la vida de aquellos dominicos reformados y también iluminó aquella sociedad.

\section{REFERENCIAS BIBLIOGRÁFICAS}

BEnAVENT, Júlia, Savonarola y España, Alzira, 2003.

Biblia Sacra iuxta Vulgatam Clementinam (A. Colunga y L. Turrado ed., Madrid, 1959). BOUREAU, Alain, La légende dorée. Le système narratif de Jacques de Vorágine, París, 1984.

COLETTI, Vittorio, L'Italiano e il modello omiletico di due predicatori a confronto: San Bernardino e Girolamo Savonarola, en The Church and the languages of Italy before the Council of Trent, Toronto, 2015, pp. 26-44.

Ferretti, Lodovico (ed.), Nella Festa di San Domenico. Sermone ineditto di Fra Girolamo Savonarola tratto dall'autografo, en Il Rosario-Memorie Domenicane, 27 (1910), pp. 381-401.

Gallego SAlvadores, Juan José, Aproximaciones a la Reforma dominicana de Raimundo de Capua y repercusiones en los dominicos de Portugal, en Arquivo Histórico Dominicano Português IV/2 (1989), pp. 219-249.

Gómez GarCÍA, Vito-Tomás. (ed.), Santo Domingo de Guzmán. Escritos de sus contemporáneos, Madrid, 2011.

interpretación según la cual La leyenda «n'est pas principalement un légendier, c'est-à-dire un catalogue hagiographique», sino algo mucho más ambicioso: «son objectif est de construire une somme qui donne la signification du temps humain [et le sacralise]». Este historiador francés a Santo Domingo lo sitúa en el quinto y último, o sea en «le temps de la pérégrination» (ibid., pp. 189-190).

32 Voy a englobarlos en los enunciados de las dos grandes partes de la ya citada excelente obra de Humbert-Marie ViCAIRE OP, Historia de Santo Domingo... [ver n. 1], que si bien fue publicada en francés en 1957 y reeditada en 2004, no ha sido todavía superada y sigue siendo de absoluta referencia. 
HERnÁNDEZ MaRTín, Ramón, La Reforma dominicana entre los Concilios de Constanza y Basilea, en Arquivo Histórico Dominicano Português, IV/2 (1989), pp. 151-179.

Huerga, Álvaro, Aproximación a la espiritualidad de Savonarola, en Angelicum 60 (1983), pp. 80-96.

HuERGa, Álvaro, Savonarola. Reformador y profeta, Madrid, 1978.

ITURGáiz, Domingo, Iconografía de San Domingo de Guzmán. La fuerza de la imagen, en Archivo Dominicano, 12 (1991), pp. 5-125.

LE GOFF, Jacques, A la recherche du temps sacré. Facques de Vorágine et la Légende dorée, París, 2011.

MaCías, José Manuel, La leyenda dorada, 2 vols., Madrid, 1990.

MARTIN, R.M. (ed.), Tractatus Pro Reformatione. Lettre de fean Uyt den Hove OP, à Charles-le-Téméraire touchant la réforme religieuse, en Analecta Sacri Ordinis Fratrum Praedicatorum, XXXI (1923) pp. 46-48, 279-304.

Mortier, R.P., Histoire des Maitres Généraux de l'Ordre des Frères Prêcheurs, t. III, Paris, 1907.

NIEVA OCAMPO, Guillermo, Virtud christiana es grande, loar la memoria de los defuntos: historia de la Orden dominica y de su Reforma en la Crónica de fray fuan de la Cruz OP (1567), en Tiempos Modernos, 8 (2015), pp. 345-368.

Propio de la ORden DE Predicadores, Liturgia de las Horas, edición típica en lengua española, Roma, 1988.

RIDOLFI, Roberto, Vita di Girolamo Savonarola, Firenze, 1981.

Roquebert, Michel, Santo Domingo. La leyenda negra, Salamanca, 2008.

SANCHIS Quevedo, Antonio, Estudios espirituales de Santo Tomás, en Teología Espiritual, 6 (1962), pp. 277-315.

Savonarola. Quaderni del quinto centenario (1498-1998), 3 vols., Bolonia, 1997.

VERDE, Armando y WeInsteIn, Donald, Savonarola. A vita, le opere, Vicenza, 1998.

VICAIRE, Humbert-Marie, Historia de Santo Domingo, Madrid, 2003. 